\title{
ANALYSIS AND DESIGN OF STEEL BRIDGE STRUCTURES WITH ENERGY ABSORPTION MEMBERS
}

\author{
Zhiyi Chen ${ }^{1}$, Hanbin $\mathrm{Ge}^{2, *}$, and Tsutomu Usami ${ }^{3}$ \\ ${ }^{1}$ Lecturer, Department of Geotechnical Engineering, Tongji University, Shanghai 200092, China \\ ${ }^{2}$ Professor, Department of Civil Engineering, Meijo University, 1-501, \\ Shiogamaguchi Tenpaku-ku, Nagoya, 468-8502, Japan \\ ${ }^{3}$ Professor, Department of Civil Engineering, Meijo University, 1-501, \\ Shiogamaguchi Tenpaku-ku, Nagoya, 468-8502, Japan \\ *(Corresponding author: E-mail: gehanbin@ccmfs.meijo-u.ac.jp)
}

Received: 6 March 2007; Revised: 8 May 2007; Accepted: 13 June 2007

\begin{abstract}
This paper aims to investigate the efficiency of energy absorption members incorporated in thin-walled steel bridge structures against major earthquakes. Energy absorption members concerned here is buckling-restrained brace (BRB), which dissipates earthquake-induced energy through metallic yielding through axial tension and compression. Dynamic nonlinear time-history analysis has been performed. It is found that such an energy absorption member is effective in mitigating earthquake hazard.
\end{abstract}

Keywords: Energy absorption member; steel bridge structures; seismic design; time-history analysis

\section{INTRODUCTION}

In recent years, various energy absorption members have been developed and used successfully into building structures to suppress structural vibrations induced by earthquakes. Of these, the hysteretic damper, whose mechanism is through material yielding to absorb earthquake-induced energy as well as increase effective damping, is the most popular one to be employed due to its reliability and low cost. Although extensive experimental and analytical researches have been conducted on building structures with such hysteretic dampers, the researches on bridge structures remain infancy $[1,2]$. Furthermore, efficiency of hysteretic dampers on seismic response reduction has been validated in comparison with the moment resisting steel structures [3] or structures with conventional steel braces [4], however, few works have addressed the efficiency between various hysteretic dampers especially when they are incorporated in bridge structures.

Three bridge forms are employed as illustrative examples. They are simple structural forms of single-deck and multi-deck bridge piers and, additionally, one complicated structural form of an arch bridge. Figure 1 shows an example of single-deck bridge piers installed with a type of hysteretic dampers, i.e., buckling-restrained brace (BRB). In the paper, the fundamental principles of structures with BRB members are introduced first. Followed is the description of design and modeling method for the BRB member. Emphases are put on the comparison of BRB efficiency in aforementioned bridge structures through times-history analyses. This investigation may provide useful messages for design of hysteretic dampers and their further laboratory experimental research.

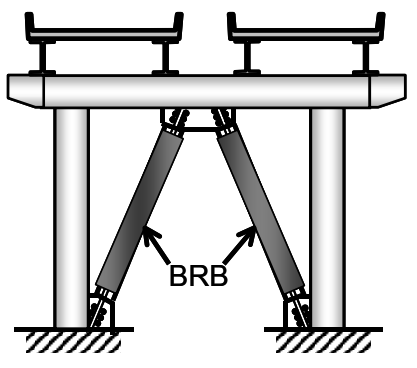

Figure 1. Single-deck Bridge Pier with Hysteretic Damping Device 


\section{FUNDAMENTAL PRINCIPLES}

Sketches of physical models for the damped structure installed with BRB are shown in Figure 2. As is seen from Figure 2, it is assumed that the BRB member itself is an entire damping device. Consequently, basic properties of the damping device have the same meaning with those of the BRB member (i.e., $F_{y, d}=F_{y, B R B}, K_{d}=K_{B R B}$ ). The BRB member is then connected as a whole with the main structure in the parallel manner. It is clear that the yield displacement of the BRB member must be smaller than that of the main structure to ensure the BRB member yields prior to the main structure during an earthquake. Namely, the design conditions of $\delta_{y, d}<\delta_{y, f}$ and $\delta_{y, d}=\delta_{y, f d}$ must be satisfied.

To compare seismic demands quantitatively, the ratio of the damper's yield strength to the main structure's lateral yield resistance, referred to as the strength ratio $\alpha_{F}$, and the ratio of the damper's initial stiffness to the main structure's lateral stiffness, referred to as the stiffness ratio $\alpha_{K}$, are generally used as design criteria $[5,6,7]$.
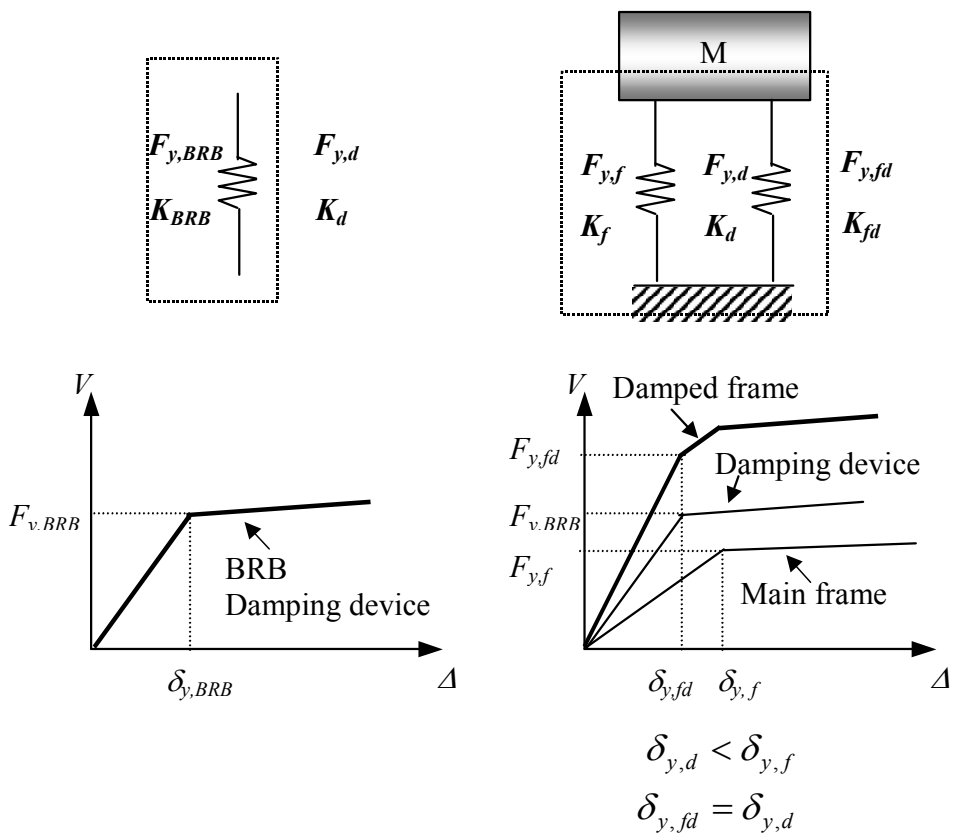

(a) BRB Damping Device (b) Damped Frame

Figure 2. Idealized SDOF System Installed with BRB

\section{DESIGN AND MODELING OF DAMPING DEVICES}

\subsection{Basic Properties of Buckling-restrained Braces}

To date, many types of BRB sections are used. The BRB used in this study is one with a flat core plate developed by Nagoya University [8,9], whose cross section is shown in Figure 3. Similar to the other BRBs, axial deformation of this BRB is allowed only at the core plate, whose severe buckling is eliminated by the exterior restraining members. The axial yield strength of the BRB, $P_{y, B R B}$, is given by

$P_{y, B R B}=\sigma_{y, B R B} \times A_{B R B}$

where $\sigma_{y, B R B}=$ tensile yield stress of steel material and $A_{B R B}=$ section area of the core plate. 
The geometric parameters and basic properties of the BRB are illustrated in Figure 4. Relationship between these parameters can be expressed as follows,

$$
F_{y, B R B}=K_{B R B} \cdot \delta_{y, B R B}, \quad \delta_{y, B R B}=\sigma_{y, B R B} \cdot \frac{2 l_{B R B}^{2}}{E L}, \quad K_{B R B}=A_{B R B} \cdot \frac{E L^{2}}{2 l_{B R B}^{3}}
$$

where $F_{y, B R B}, \delta_{y, B R B}$, and $K_{B R B}=$ the lateral yield strength, displacement, and elastic stiffness of a pair of BRBs, respectively; $l_{\mathrm{BRB}}=$ length of a BRB; $L=$ the structure span.

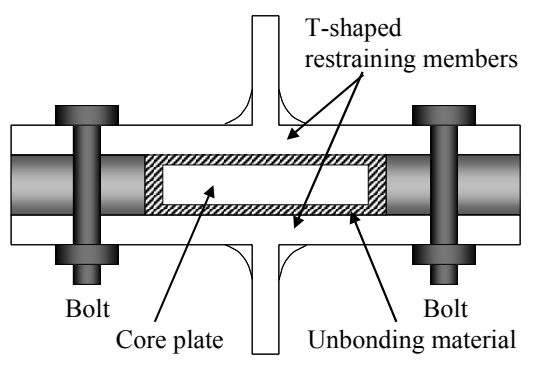

Figure 3. Buckling-restrained Brace (BRB)

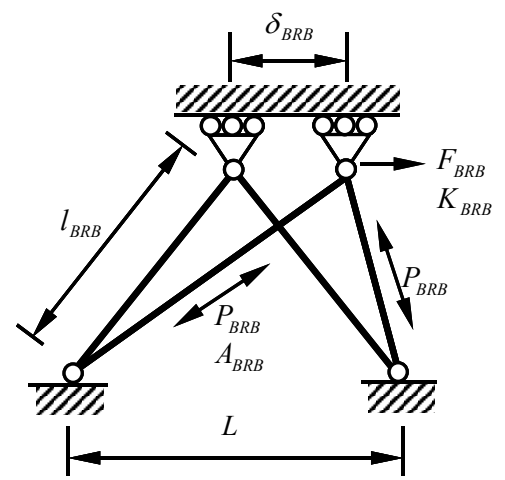

Figure 4. Schematic Diagram for BRB Deformation

\subsection{Hysteretic Model and FE Modeling of BRB}

Figure 5 shows a finite element model of the single-deck bridge pier with BRB, referred to as BRB model later. $\mathrm{BRB}$ is directly modeled by the truss element, only carrying axial tension and compression without local bucking. In this study, the core plates of the BRB employed are made of SS400 steel. For such a BRB member, a bilinear stress-strain relationship with kinematic hardening rule, as shown in Figure 6, is suggested [8, 9].

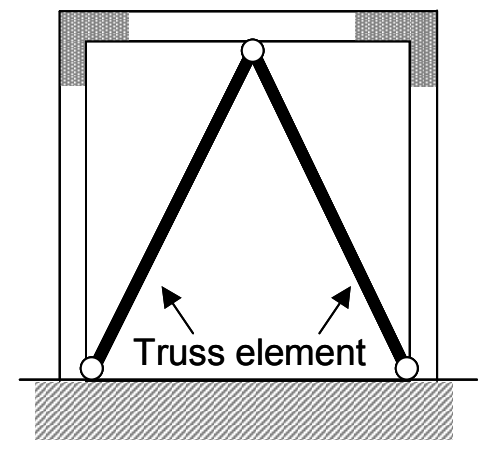

Figure 5. BRB Model

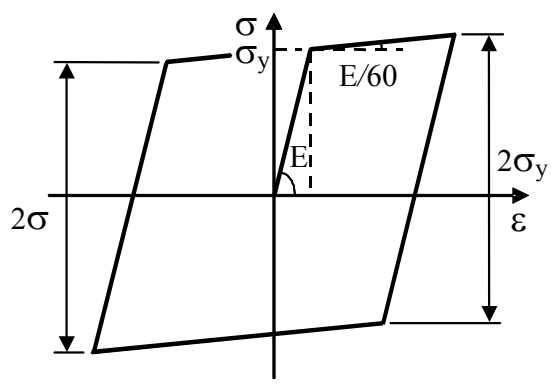

Figure 6. Hysteretic Model with Kinematic Hardening Rule

\subsection{Design Order and Commentary for BRB in Seismic Design Process}

Knowing the predefined strength ratio $\alpha_{F}$ and the stiffness ratio $\alpha_{K}$ as well as corresponding strength and stiffness of the main structure, $F_{y, B R B}$ and $K_{B R B}$ can easily be determined. Then, the basic properties of BRB such as $\sigma_{y, B R B}$ and $A_{B R B}$ can be easily established from Eq. 2 . Note that such design process will cause variation of $\sigma_{y, B R B}$. In practical design, steel material is usually determined at the beginning, followed by the establishment of $\delta_{y, B R B}$. In other words, $A_{B R B}$ becomes the single adjustable parameter in design of BRB damping devices. 


\section{DESIGN AND ANALYTICAL MODELING OF STEEL BRIDGE STRUCTURES}

\subsection{Design and Analytical Modeling of Single-deck Bridge Piers}

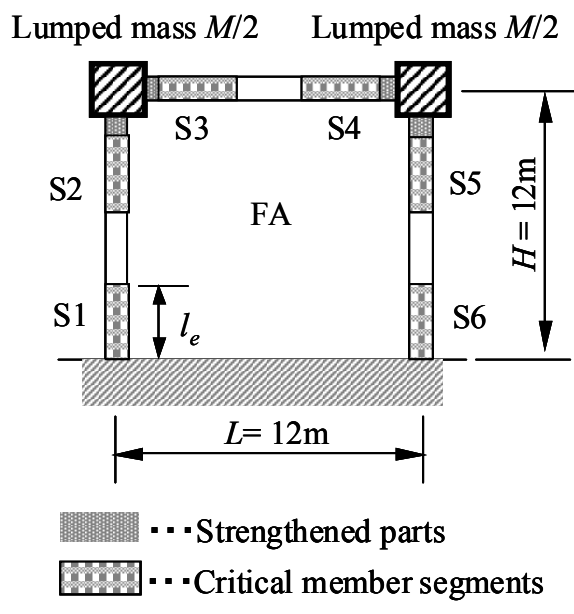

(a)

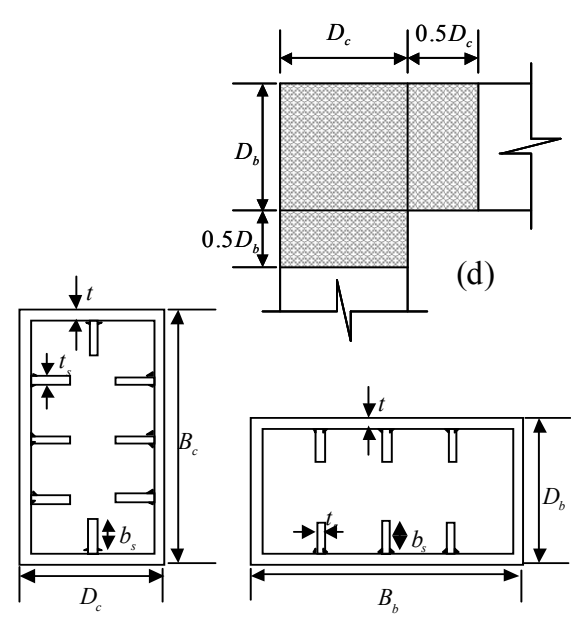

(c)

Figure 7. Single-deck Bridge Pier: (a) Layout; (b) Pier Section; (c) Girder Section; and (d) Details at Strengthened Corner

The analytical model to be investigated is single-deck steel bridge piers of portal frame type, which are widely used in Japan to support elevated expressways. The general layout and finite element model are illustrated in Figure 7(a). The piers and girders have uniform stiffened box cross-sections, as shown in Figures 7(b) and (c). Since this type of portal frames is commonly heavy burdened, the plates at the pier-girder connection parts should be strengthened by doubling the plate thickness in order to avoid shear failure. The detailed size of strengthened parts is shown in Figure 7(d). The portal frame is designed in accordance with the Seismic Coefficient Method [10,11], assuming regional class A and ground class II. Detailed information about the frame is summarized in the column titled by F1 in Table 1. In Table 1, the basic properties of the main frame (such as the initial yield displacement and strength, the ultimate displacement and strength) are determined with a pushover analysis as presented in a previous study [12], being somewhat analogous to those provided by Eurocode 8 [13], FEMA 356 [14], and Chopra and Goel [15].

Two-dimensional Timoshenko beam element of type B21 provided in the ABAQUS element library [16] is used to model the piers and girder, accounting for shear deformation. Each pier and girder of the main frame is divided into 20 elements: 5 elements for each critical member segment, 2 elements for strengthened parts, and the remains for the other parts. Here, critical member segments are denoted by the dotted sections at the pier bases and adjacent to the rigid corners, as shown in Figure 7(a).

\subsection{Design and Analytical Modeling of Multi-deck Bridge Piers}

Since a highway bridge system is commonly composed of thin-walled members and a popular format is low-rise (1 3 decks) framing type, double-deck and tri-deck bridge piers of portal frame types are considered here, as shown in Figure 8. It is assumed that the double-deck and tri-deck portal frames considered here have girders and piers of the same section as the preceding single-deck portal frame. Thus, each deck has the same yield inter-deck force and stiffness. The basic properties of multi-deck portal frames, denoted by F2 and F3, are listed in Table 1. The masses subjected on the top of columns are the same in each level. 


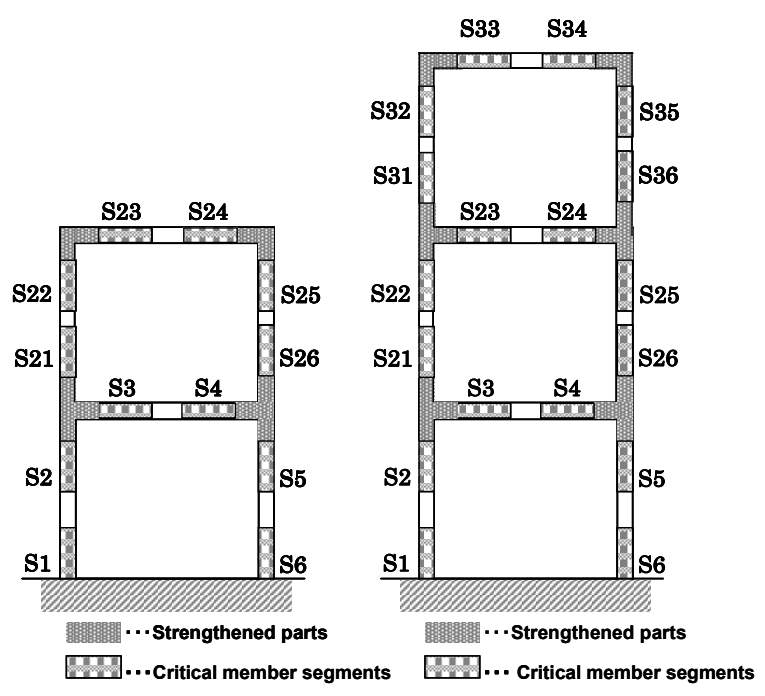

(a)

(b)

Figure 8. Multi-deck Steel Bridge Piers: (a) Double-deck; (b) Tri-deck

Table 1. Structural Parameters and Basic Properties of the Main Frames Main Frame

\begin{tabular}{lccc}
\hline Items & F1 & F2 & F3 \\
\hline Steel grade & SM490 & SM490 & SM490 \\
Height, $H(\mathrm{~m})$ & 12 & $12 \times 2$ & $12 \times 3$ \\
Length, $L(\mathrm{~m})$ & 12 & 12 & 12 \\
Total deck mass, $M(\mathrm{ton})$ & 2042 & 2034 & 2895 \\
Initial yield displacement, $\delta^{\text {in }}{ }_{y, f}(\mathrm{~m})$ & 0.078 & 0.137 & 0.178 \\
Initial yield strength, $V_{y, f}^{\text {in }}(\mathrm{kN})$ & 6758 & 5939 & 5129 \\
Ultimate displacement, $\delta_{u, f}(\mathrm{~m})$ & 0.418 & 0.518 & 0.549 \\
Ultimate strength, $V_{u, f}(\mathrm{kN})$ & 11836 & 10884 & 9557 \\
Period, $T_{f}(\mathrm{sec})$ & 0.97 & 1.23 & 1.77 \\
\hline
\end{tabular}

\begin{tabular}{lcclcc}
\hline \multicolumn{1}{c}{ Pier } & & & \multicolumn{2}{c}{ Girder } \\
\cline { 1 - 2 } \cline { 5 - 6 } Items & Value & & Items & Value \\
\cline { 1 - 2 } Width, $B_{c}(\mathrm{~mm})$ & 2000 & & Width, $B_{b}(\mathrm{~mm})$ & 2000 \\
Depth, $D_{c}(\mathrm{~mm})$ & 1000 & & Depth, $D_{b}(\mathrm{~mm})$ & 1000 \\
Thickness, $t(\mathrm{~mm})$ & 32 & & Thickness, $t(\mathrm{~mm})$ & 32 \\
Flange slenderness, $R_{f c}$ & 0.34 & & Flange slenderness, $R_{f b}$ & 0.34 \\
Web slenderness, $R_{w c}$ & 0.34 & & Web slenderness, $R_{w c}$ & 0.78 \\
Aspect ratio of flange,,$\alpha_{f c}$ & 1.0 & & Aspect ratio of flange, $\alpha_{f b}$ & 0.5 \\
Aspect ratio of web,,$\alpha_{w c}$ & 0.5 & & Aspect ratio of web, $\alpha_{w b}$ & 0.83 \\
No. of flange sub-panels, $n_{f c}$ & 2 & & No. of flange sub-panels, $n_{f b}$ & 4 \\
No. of web sub-panels, $n_{w c}$ & 4 & & No. of web sub-panels, $n_{w b}$ & 1 \\
Stiffener slenderness,, $\bar{\lambda}_{s c}$ & 0.89 & & Stiffener slenderness, $\bar{\lambda}_{s b}$ & 0.72 \\
Stiffener width, $b_{s}(\mathrm{~mm})$ & 140 & & Stiffener width, $b_{s}(\mathrm{~mm})$ & 140 \\
Stiffener thickness, $t_{s}(\mathrm{~mm})$ & 32 & & Stiffener thickness, $t_{s}(\mathrm{~mm})$ & 32 \\
\hline
\end{tabular}




\subsection{Design and FE Modeling of Arch Bridge}

An upper-deck arch bridge mainly composed of reinforced concrete (RC) deck slab, steel girders and single span steel arch ribs is modeled. A total length of the bridge is $173.0 \mathrm{~m}$, and a two end-hinged steel arch has a span of $114.0 \mathrm{~m}$ with a rise at the crown of $16.87 \mathrm{~m}$, giving a rise-span ratio of 1/6.76. Figure 9 shows the established FE model, where 3D Timoshenko beam elements of type B31 provided in the ABAQUS program [16] are employed to model the deck slab, girders, columns (vertical members), arch ribs and transverse bracings while 3D truss elements of type T3D2 for diagonals. In this analytical model, there are totally 884 elements with 462 nodes. More information of this bridge is referred to the literatures $[2,17]$.

\subsection{Input Earthquakes}

Three strong ground motions are adopted in the time-history analyses. They are ground motions recorded from the 1995 Hyogoken-Nanbu Earthquake at JR West Japan Takatori and at Fukiai supply station of Osaka Gas Corporation. Their accelerograms are shown in Figure 10, with the peak accelerations of $6.73 \mathrm{~m} / \mathrm{sec}^{2}$ (JRT-EW-M), $6.87 \mathrm{~m} / \mathrm{sec}^{2}$ (JRT-NS-M), and $7.36 \mathrm{~m} / \mathrm{sec}^{2}$ (FUKIAI-M), respectively.

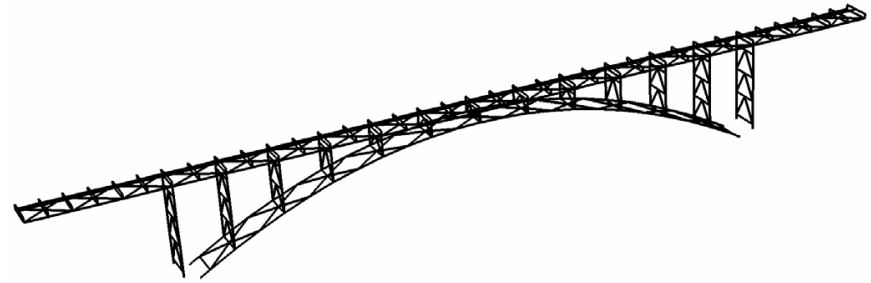

Figure 9. FE Model of Arch Bridge

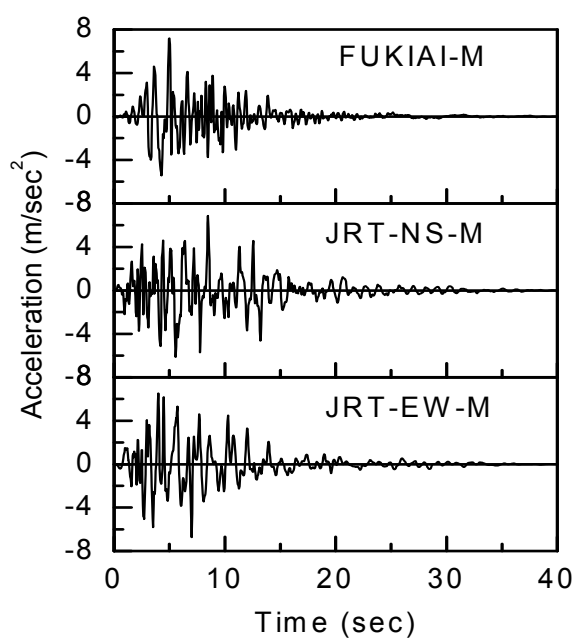

Figure 10. Input Earthquakes

\section{EFFICIENCY OF DAMPERS INSTALLED IN BRIDGE STRUCTURES}

Dynamic time-history analyses are performed using the general-purpose finite element program ABAQUS [16]. In order to trace the material cyclic behavior accurately, the modified two-surface model [18] is employed. Rayleigh damping, which is usually utilized in dynamic analysis, consists of mass proportional damping and stiffness proportional damping. Here, mass proportional damping of 5 percent is used whereas inherent stiffness proportional damping is set as zero since it is neglectable if compared to the significant equivalent viscous damping due to yielding of hysteretic dampers.

\subsection{Efficiency of Dampers Installed in Single-deck Bridge Piers}

In this section, the efficiency of dampers installed in single-deck bridge piers is investigated according to the strength ratio, $\alpha_{F}$ and various strong ground motions.

The time-history analysis results for single-deck bridge piers subjected to JRT-EW-M accelerogram are illustrated in Figure 11, according to $\alpha_{F}$. Seen from Figure 11(a), the maximum top 
displacement, is sharply decreased from $260 \mathrm{~mm}$ in Bare model (a portal frame without damping devices $)$ to $131 \mathrm{~mm}\left(\alpha_{F}=0.5\right), 77 \mathrm{~mm}\left(\alpha_{F}=1.0\right)$, and $74 \mathrm{~mm}\left(\alpha_{F}=1.5\right)$ in BRB models. These values are below $1.7 \delta_{y}$ (about $133 \mathrm{~mm}$ for the example piers), which denotes light damage to the steel bridge piers of portal frame type [17]. Referring to Figure 11(b), in the case of $\alpha_{F}=0.5$, the normalized axial deformation of $\left.\mathrm{BRB}, \varepsilon_{\max } / \varepsilon_{y}\right)_{\mathrm{BRB}}$, is 28.2. As $\alpha_{F}$ is increased from 0.5 to 1.0 , a rapid decrease of deformation of dampers is observed, indicating a decrease in damage to the dampers. Meanwhile, increasing $\alpha_{F}$ from 1.0 to 1.5 , the peak responses are improved a little. When $\alpha_{F}$ equals 1.5, the main frame remains in elastic range. This fact indicates that the main frames can remain intact even under major earthquake. Energies dissipated by the dampers are shown in Figure 11(c), and the stable energy dissipating capacity of the dampers is confirmed in all the cases.

Comparison of the efficiency of dampers under various strong ground motions are shown in Figure 12. The square-shaped frame with $\alpha_{F}=1.0$ is adopted. Clearly, top displacement demands of BRB models have sharply decreased compared with those of the Bare model as shown in Figure 12(a). Meanwhile, the average compression strains as shown in Figure 12(c) have decreased within $2 \varepsilon_{y}$, which denotes light damage to the steel bridge piers of portal frame type [17]. Figure 12(b) indicates that the total base shear resulting from the added stiffness is no more than twice of the original one. Thus, the shear force to be transmitted to foundations is still in the range of the original design force. No additional foundation retrofit is required.

\subsection{Efficiency of Dampers Installed in Multi-deck Bridge Piers}

Dynamic analysis results of multi-deck bridge piers are summarized in Table 2. Major findings obtained from single-deck ones can be extended to multi-deck ones. Distinguished from single-deck ones, multi-deck bridges piers have a particular problem of distribution of damping devices into the levels. Referring to the plastic energy dissipated by the dampers at each level as shown in Table 2, in the case of F2-BRB-03, the energy dissipated averagely by the dampers in the first level and the second level equal to 0.470 and 0.529 , respectively. This case has shown suitable distribution of stiffness and strength of damping devices. However, the case of F2-BRB-05 exhibits the highly unequal distribution of plastic energy. The damper in the first level dissipates 0.225 of the total plastic energy while in the second level it is 0.739 . Although the strength ratio increases from 0.3 to 0.5 , the F2-BRB-05 case produces larger strains and top displacements than the F2-BRB-03 case. Non-uniform distribution of dissipated energy can be found in F3-BRB-03 as well. The optimum distribution of damping devices into bridge structures will be one of the important issues in the future research.

\subsection{Efficiency of Dampers Installed in Arch Bridges}

As shown in Figure 13, time-history analyses are conducted on the original arch bridge as well as two bridges with some diagonal braces being replaced by BRBs. In Figure 13(a), over-plasticization occurs at the side pier and arch rib bases, which may make the original bridge fail during a major earthquake. Hence two upgrading schemes are performed. In Figure 13(b), lateral braces of the side piers are replaced by six BRBs to reduce the strain demand. In Figure 13(c), additional six BRBs replace the diagonals near two arch rib bases. Differing from the previous direct design, design of BRB members in arch bridges involves iterations due to the structural complexity. The BRB members are expected to behave in the elastic range under moderate earthquakes, while yield prior to other members when subjected to major earthquakes.

Performance upgrading effect of replacing by BRB can easily be found from analysis results. The maximum axial force demand at the side pier base is decreased from about $P_{y, B R B}$ in the Original Model to lower than $0.5 P_{y, B R B}$ in the two Upgrading Models. Seen from Figure 13(b) in Upgrading 
Model 1, placement of BRB members only at side pier location decreases the strain demand at side pier base sharply from $-29 \varepsilon_{y}$ to $-2.79 \varepsilon_{y}$. However, a decrease of stiffness in this region results in an increase of strain demand at the arch rib base. The strain demand at the arch rib base increases from $-2.51 \varepsilon_{y}$ in the Original Model to $-4.49 \varepsilon_{y}$ in Upgrading Model 1 . On the other hand, in Upgrading Model 2 as shown in Figure 13(c), additional placement of BRB members in arch ribs decreases the strain demand at the side pier base to $-1.38 \varepsilon_{y}$ and decreases the strain demand at the arch rib base low to the elastic range. Large plasticity is concentrated at the BRB members, where the strain demand is about $-7.85 \varepsilon_{y}$.
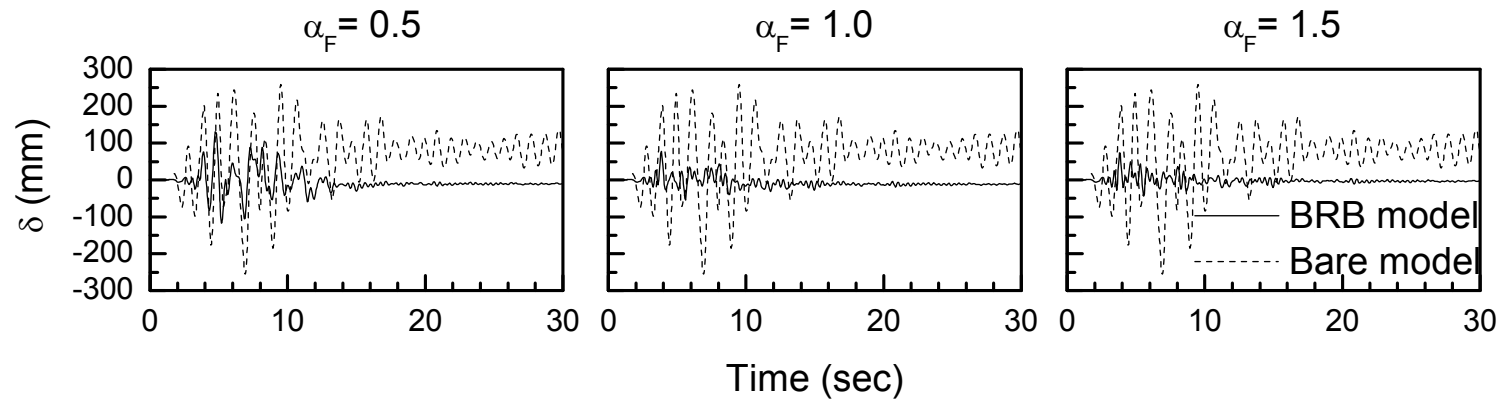

(a)
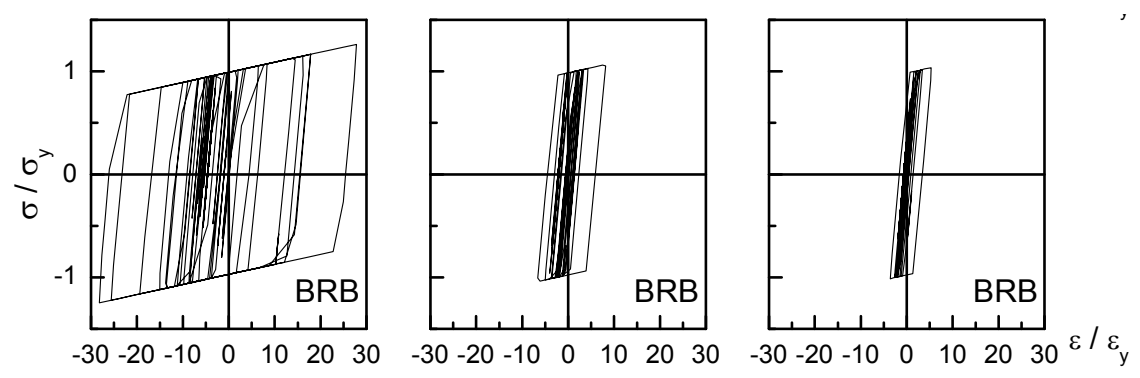

(b)

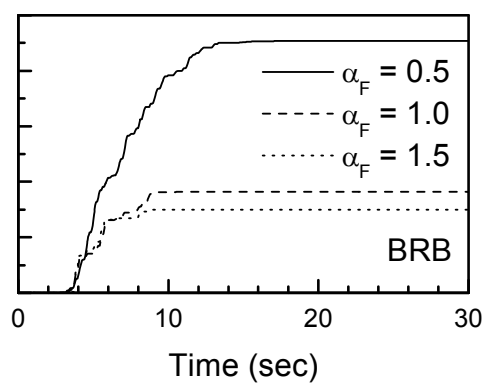

(c)

Figure 11. Responses from Time-history Analysis: (a) Top Displacement Responses; (b) Stress-strain Responses of Dampers; and (c) Energy Dissipated by Dampers 


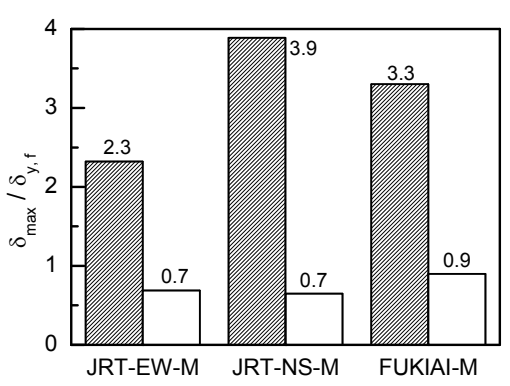

(a)

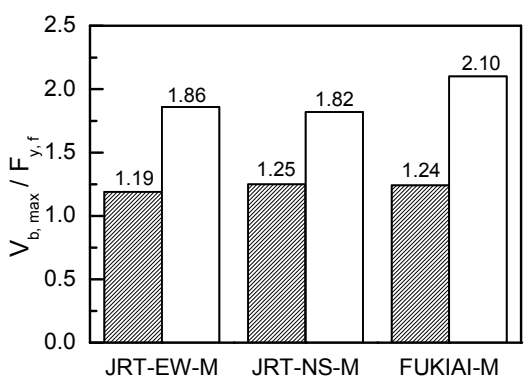

(b)

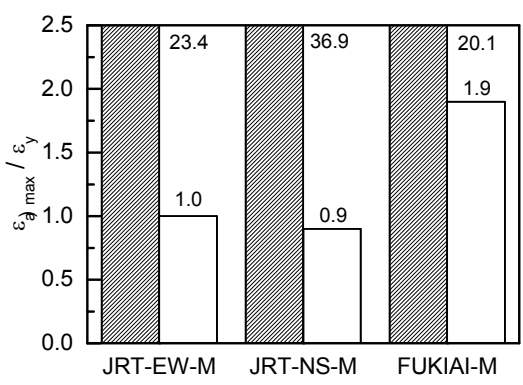

(c)

Figure 12. Comparison under Various Strong Earthquakes: (a) Normalized Top Displacement Demands; (b) Normalized Base Shear Demands; and (c) Normalized Average Compression Strain Demands at Pier Bases

Table 2. Summary of Design and Analysis Results for Multi-deck Bridge Piers with or without Dampers

\begin{tabular}{|c|c|c|c|c|c|c|c|c|c|}
\hline \multirow[b]{2}{*}{ Model } & \multicolumn{9}{|c|}{ Time-history analysis results } \\
\hline & $\frac{\varepsilon_{a) \max }}{\varepsilon_{y}}$ & $\begin{array}{l}\delta_{\max } \\
(\mathrm{m})\end{array}$ & $\begin{array}{c}V_{b, \max } \\
\left(\times 10^{3} \mathrm{kN}\right)\end{array}$ & $\left.\frac{\varepsilon_{\max }}{\varepsilon_{y}}\right)_{B R B}$ & $\frac{E_{f}}{E_{p}}$ & $\frac{E_{d, 1}}{E_{p}}$ & $\frac{E_{d, 2}}{E_{p}}$ & $\frac{E_{d, 3}}{E_{p}}$ & $\begin{array}{c}E_{p} \\
\left(\times 10^{6} \mathrm{~J}\right)\end{array}$ \\
\hline F2-Bare & 27.8 & 0.531 & 11.1 & - & 1.000 & - & - & - & 26.7 \\
\hline F2-BRB-03 & 1.11 & 0.154 & 16.3 & 5.2 & 0.001 & 0.470 & 0.529 & - & 8.59 \\
\hline F2-BRB-05 & 1.65 & 0.169 & 23.1 & 4.6 & 0.006 & 0.255 & 0.739 & - & 6.67 \\
\hline F3-Bare & 21.5 & 0.699 & 10.7 & - & 1.000 & - & - & - & 18.7 \\
\hline F3-BRB-03 & 1.38 & 0.289 & 19.4 & 9.4 & 0.002 & 0.193 & 0.484 & 0.321 & 11.6 \\
\hline
\end{tabular}

Note: F2 and F3 stand for double and tri-deck bridge piers, respectively. Bare and BRB represent piers without and with BRB members, respectively. The numbers (03 and 05) represent the values of the strength ratio $\alpha_{F}$ at each level. $\varepsilon_{a \text { ) max }} / \varepsilon_{y}$ represents the normalized average compression strain measured at critical member segments; $\delta_{\max }$ is top displacement demand; $V_{b, \max }$ is base shear demand; $\left.\varepsilon_{\max } / \varepsilon_{y}\right)_{B R B}$ represents the normalized axial strain demand of $\mathrm{BRB} ; E_{p}$ represents the total plastic energy; $E_{f}$ and $E_{d, i}$ represent plastic energy in the main structure and in the dampers of each level, respectively, where $i=1,2$, and 3 .

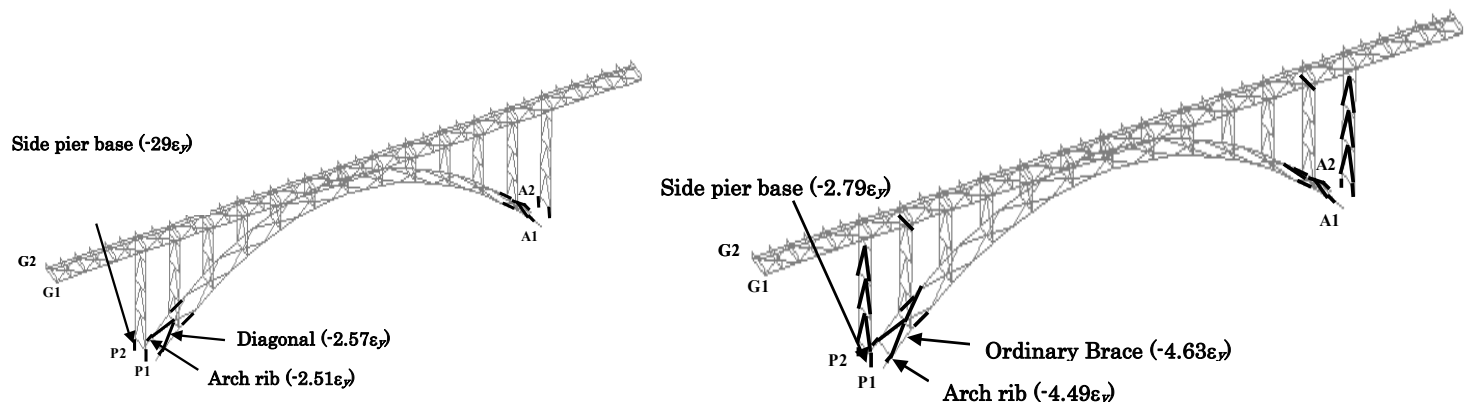

(a) Original Model

(b) Upgrading Model 1 


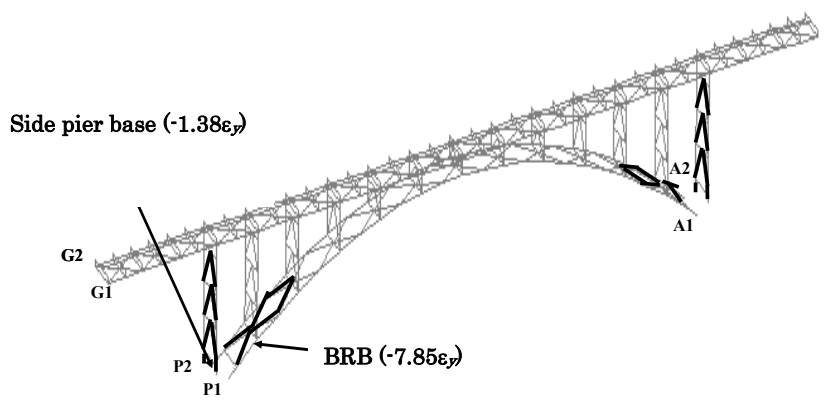

(c) Upgrading Model 2

Figure 13. Yielded Members in the Original and Upgrading Models

\section{SUMMARY AND CONCLUSIONS}

This paper presented an investigation on the seismic upgrading efficiency of the buckling-restrained braces (BRB) under major earthquakes. Three types of bridge structures are used as illustrative examples. 2D and 3D finite element models are established and dynamic nonlinear time-history analyses are performed. It has been shown that BRB members are effective in dissipating earthquake-induced energy and eliminating or limiting damage to the main structures.

\section{REFERENCES}

[1] Zahrai, S.M. and Bruneau, M., "Ductile End-diaphragms for the Seismic Retrofit of Slab-on-girder Steel Bridges”, Journal of Structural Engineering, ASCE, 1999, Vol. 125, No. 1, pp. 71-80.

[2] Usami, T., Lu, Z.H. and Ge, H.B., "A Seismic Upgrading Method for Steel Arch Bridges Using Buckling-restrained Braces", Earthquake Engineering and Structural Dynamics, 2005, Vol. 34, pp. 471-496.

[3] Yamaguchi, M., Yamada, S., Maeda, Y., Ogihara, M., Takeuchi, T., Narikawa, M., Nakashima, M. and Wada, A., "Evaluation of Seismic Performance of Partial Frames using the Shaking Table Test-Seismic Performance of Moment Resisting Steel Frame with Damper: Part 2", Journal of Structural and Construction Engineering, AIJ, 2001, Vol. 547, pp. 153-160.

[4] Tena-Colunga, A. and Vergara, A., "Comparative Study on the Seismic Retrofit of a Mid-rise Steel Building: Steel Bracing vs Energy Dissipation”, Earthquake Engineering and Structural Dynamics, 1997, Vol. 26, pp. 637-655.

[5] Ye, L.P. and Ouyang, Y.F. "Dual Seismic Structure System and its Parametric Analysis", Engineering Mechanics, 2000, Vol. 17, No. 2, pp. 23-29.

[6] Inoue, K. and Kuwahara, S., "Optimum Strength Ratio of Hysteretic Damper", Earthquake Engineering and Structural Dynamics, 1998, Vol. 27, pp. 577-588.

[7] Yamaguchi, H. and Ashraf, E.A., "Effect of Earthquake Energy Input Characteristics on Hysteretic Damper Efficiency", Earthquake Engineering and Structural Dynamics, 2003, Vol. 32, pp. 827-843.

[8] Kato, M., Usami, T., Kasai, A. and Chusilp, P., “An Experimental Study on Cyclic Elasto-plastic Behavior of Buckling Restrained Brace Members", Proceedings of the 6th Symposium on Ductility Design Method for Bridges, Ductility Design Subcommittee, Earthquake Engineering Committee, JSCE, Tokyo, Japan, 2003, pp. 345-350.

[9] Usami, T., Kasai, A. and Kato, M., "Behavior of Buckling-restrained Brace Members", Behaviour of Steel Structures in Seismic Areas, STESSA, Naples, Italy, 2003, pp. 211-216. 
[10] JRA, "Design Specifications of Highway Bridges-Part V Seismic Design", Japan Road Association, Tokyo, Japan, 2002a. (in Japanese)

[11] JRA, "Design Specifications of Highway Bridges-Part II Steel Bridges", Japan Road Association, Tokyo, Japan, 2002b. (in Japanese)

[12] Usami, T., Zheng, Y. and Ge, H.B., "Seismic Design Method for Thin-walled Steel Frame Structures", Journal of Structural Engineering, ASCE, 2001, Vol. 127, pp. 137-144.

[13] Eurocode 8, "Design of Structures for Earthquake Resistance. General Rules, Seismic Actions and Rules for Buildings", British Standards Institution, London, 2003.

[14] FEMA 356, "Prestandard and Commentary for the Seismic Rehabilitation of Buildings", Federal Emergency Management Agency, Washington DC, 2000.

[15] Chopra, A.K. and Goel, R.K., "A Modal Pushover Analysis Procedure for Estimating Seismic Demands for Buildings", Earthquake Engineering and Structural Dynamic, 2002, Vol. 31, pp. 561-582.

[16] ABAQUS/Analysis user's Manual-Version 6.4. ABAQUS, Inc., Pawtucket, R.I., 2003.

[17] Usami, T. ed., "Seismic Performance-based Verification Procedures and Upgrading Measures for Civil Engineering Steel Structures", Subcommittee for Seismic Design of Steel Bridges, Task Committee of Performance-Based Seismic Design Methods for Steel Bridges, Tokyo, 2003.

[18] Shen, C., Mamaghani, I.H.P., Mizuno, E., and Usami, T., "Cyclic Behavior of Structural Steels. II: Theory”, Journal of Engineering Mechanics, ASCE, 1995, Vol. 121, No. 11, pp. 1165-1172. 